Hispania Sacra, Estudios de Edad Moderna, 58

117, enero-junio 2006, 69-100, ISSN: 0018-215-X

\title{
SOBRE EL NACIMIENTO Y PROCEDENCIA DE SAN JUAN DE DIOS Y SU OBRA
}

\author{
POR
}

\author{
JosÉ LUIS MARTÍNEZ GIL OH
}

Curia General $\mathrm{OH}$

\section{RESUMEN}

Estudio de la figura de san Juan de Dios enmarcado en el contexto histórico de la Granada de mediados del siglo XVI. Se abordan, desde una perspectiva cronológica, los principales aspectos de la biografía del santo, así como su obra asistencial respecto a pobres y enfermos, profundizando en la situación de los hospitales en Granada en este período.

PAlabras ClaVE: San Juan de Dios, Granada, Siglo XVI, Obra asistencial, Enfermos, Pobres, Caridad.

\begin{abstract}
This article studies the figure of St. Juan de Dios inside the historical context of Granada during the middle of XVIth century. The article tackles, from a chronological perspective, the main subjects of the biography of St. Juan and this assitencial work with poors and ills. The author goes more deeply into the situation of the hospitals in Granada in St. Juan de Dios day.
\end{abstract}

KEY WORDS: St. Juan de Dios, XVI ${ }^{\text {th }}$ century, Assistencial work, ills, poors, charity.

\section{JUAN DE DIOS, UN HOMBRE DE SU TIEMPO}

Juan Ciudad es un hombre de bien y se le recuerda porque supo hacerlo a todos. Su lema y su trabajo «haceos bien» lo vivió con los pobres sirviéndoles 
por amor de Dios. Es lo que manifiesta el Espíritu Santo: «se hace bien a sí mismo el varón misericordioso» $(\operatorname{Pr} 11,17)$. Él lo realizó en su tiempo. Juan tuvo un compromiso solidario con los hombres pobres más pobres. José Ignacio Tellechea dice de Ignacio de Loyola: «Su época no es suya, porque no se la apropia. Son acontecimientos simultáneos, sincrónicos, yuxtapuestos a tenor de imperativos de calendario o de sinopsis cronológica de manual de historia» ${ }^{1}$; destacando también, «por comprometerse siempre todo entero, jamás calcula su pérdida y su ganancia» ${ }^{2}$, expresión que hace suya también Juan, «que ellos no pierdan y yo no gane». El carisma es gracia, belleza, don, regalo del Espíritu (cf. 1 Co 12, 27-31); al mismo tiempo: llamada, vocación al servicio de la comunidad $(R m 1,1)$.

La historia nos presenta hombres y mujeres que han vivido su ser, su ideal, en la normalidad de la existencia, según la siguación y acontecimientos de su tiempo. Existir es modificarse. Modificarse es madurar y madurar es recrearse a sí mismo. Descubramos la gloria de Dios en Juan, el hombre viviente, al servicio de Dios y de los hombres y que siguió sus designios.

\section{FUENTES DOCUMENTALES}

Las fuentes o depósitos documentales donde duermen archivadas las huellas de Juan de Dios son:

- Sus cartas y Memoriales a Felipe II en 1548.

- El manuscrito de Relaciones Histórico-Geográfico-Estadísticas de los pueblos de España. Hechas por iniciativa de Felipe II, «Reino de Toledo», publicado por el Consejo Superior de Investigaciones Científicas, Madrid, $1951^{3}$, conservado en la Biblioteca de San Lorenzo del Escorial.

- La biografía escrita por Castro, quien investiga y recoge los recuerdos de Juan apenas pasados treinta años de la muerte del santo.

- Los procesos de beatificación substanciados a la distancia ya respetable de ochenta años.

\footnotetext{
1 José Ignacio Tellechea Idígoras, Ignacio de Loyola, solo y a pie, Salamanca, 1997, 131.

2 Ibid., 120.

3 Carmelo ViÑas y Ramón PaZ, Relaciones Histórico-Geográfico-Estadísticas de los pueblos de España. Hechas por iniciativa de Felipe II, Reino de Toledo, Consejo Superior de Investigaciones Científicas, Madrid, 1951. 
- Ahora contribuyo con mi Tesis Doctoral ${ }^{4}$ publicada recientemente con una nueva aportación de nuevos e inéditos documentos sobre la vida y obra de Juan de Dios: Bulas, Memoriales y cartas regias.

La biografía de Castro permaneció muchísimo tiempo olvidada en los siglos sucesivos, ya que le robaron el puesto las «biografías barrocas» de Juan de Dios, compuestas por Dionisio de Celi y Antonio Govea, devotísimas, bien intencionadas, pero plagadas de milagros y apariciones carentes de fundamento histórico. Desfiguraron la verdadera imagen del «bendito Juan».

Como era de suponer, estas biografías milagreras sirvieron materiales para las dos o tres docenas de «vidas» del santo publicadas con estilo popular de entonces acá en varios idiomas.

Me basaré en el presente trabajo documentalmente de la fuente del documento del Escorial publicado en las Relaciones Histórico-Geográficas-Estadísticas del Reino de Toledo. De la primera biografía del P. Francisco Castro en las citas y pasos históricos, junto con la Cronología Hospitalaria del P. Juan Santos. La Cronología Aplicada del P. Rafael Saucedo, del que haré singular mención por ser uno de los mejores conocedores de la obra de Juan de Dios. En la parte espiritual seguiré al P. Gabriel Russotto. De la parte histórica seguiré las pautas del inolvidable P. Juan Ciudad. Con el Profesor Manuel Gómez Moreno veremos la parte de historia de la Orden Hospitalaria de S. Juan de Dios, Granada y la singular obra del santo hospitalario.

\section{OTRAS FUENTES}

\subsection{Oscuridad de las Fuentes}

El primer documento escrito sobre el origen de Juan de Dios es el que aportan Carmelo Viñas y Ramón Paz, en: «Relaciones Histórico-Geográfico-Estadísticas de los pueblos de España. Hechas por iniciativa de Felipe II, Reino de Toledo» publicado por el Consejo Superior de Investigaciones Científicas, Madrid, $1951^{5}$.

Es el documento más próximo a su muerte, escrito antes de la vida de Castro, se escribía en contestación a un cuestionario de interrogaciones ordenadas por el meticuloso Felipe II. Hemos visto la intervención del párroco y de tres personas solventes, tan sólo a veintiséis años después de la muerte de Juan de

\footnotetext{
4 José Luis Martínez Gil OH, San Juan de Dios Fundador de la Fraternidad Hospitalaria, BAC, Madrid, 2002.

5 Ibid., 259.
} 
Dios. Hay que pensar que estaban en lo cierto, porque cuando hacen mención de otras personas de relieve que no fueron naturales del pueblo, y que en él residieron, así lo hacen constar; por ejemplo, al dar el nombre del protonotario Garci Ximénez, del que dicen: «que aunque no fue natural desta villa, sino de la ciudad de Toledo, residió en esta villa estos cincuenta años» 6 .

Este documento no ha sido conocido hasta su publicación en 1951 y se ha procurado silenciar, no sé los intereses, pero sí la rigurosidad histórica que aún sigue irgnorándose por algunos escritores.

Debemos señalar que durante su vida en Casarrubios y en Oropesa no se señala por nada digno de consignarse en las relaciones. La fama surge y se extiende a raíz del primer hospital que funda en Granada, en 1535; por ello se hacen eco los de Casarrubios, en su memoria vive el nombre de Juan de Dios veinticinco años después de su muerte. Hay que tener en cuenta que en el mismo pueblo de Casarrubios abundan por aquel entonces los ejemplos de personas de allí naturales que fundan hospitales, colegios y capillas en la propia localidad o en la de los alrededores y que «vivieron gastando en pobres su renta» ${ }^{7}$.

Castro no menciona el año del nacimiento de Juan, ni el nombre de sus padres y dice «que es de nación portuguesa..., de un pueblo llamado Montemayor el Nuevo» ${ }^{8}$.

\subsection{Casarrubios del Monte (Toledo), nuevos caminos de búsqueda}

El problema del nacimiento de Juan de Dios es serio, pide aclararse, quizá los años maduren y se esclarezca en su totalidad. Castro ya tuvo dificultades en recopilar datos para la biografía. Bien es cierto que entonces no se llevaba aún los registros parroquiales, que empezaron a entrar en vigor en 1520. Con lo que no era posible establecer documentación certera sobre ello. Pero sí existen los censos.

Juan de Dios y el hospital, no habían pasado desapercibidos, habían calado muy profundamente en el recuerdo del pueblo y en España.

No olvidemos que entonces cuando se realizan los censos era todavía simplemente Juan de Dios, pues el proceso de beatificación comenzó hacia el 1622. De no haber sido verdaderamente natural de ella ya que entre sus convecinos contaban con personas de más relieve social e intelectual que practicaban

\footnotetext{
${ }^{6}$ Benito Revuelta, San Juan de Dios, Temas Españoles, n. ${ }^{\circ}$ 395, Madrid, 1959, 9.

7 Ibid., 9.

8 Francisco de CASTro, Historia de la Vida y santas obras de San Juan de Dios y de la Institución de su Orden y principios de su Hospital, Edición facsímil, Córdoba, 1995, cap. 1, 1v.
}

Hispania Sacra, Estudios de Edad Moderna, 58

117, enero-junio 2006, 69-100, ISSN: 0018-215-X 
en alto grado la virtud de la caridad, no lo hubieran citado. Así lo confirma Benito Revuelta: Por consiguiente, parece que no cabe dudar que Juan de Dios, nació en Casarrubios, Toledo, en España 9 .

\subsection{Juan Ciudad y Casarrubios del Monte (Toledo)}

La fecha 1575 nos sitúa veinticinco años antes de la muerte de San Juan de Dios. Y siete años antes de que Francisco de Castro redacte la biografía del santo. Por tanto, igual a la misma vera de los hechos.

El censo de Felipe II lleva por título Relaciones histórico geográficas de los pueblos de España. Este documento, que yo llamo del Escorial por encontrarse en la Biblioteca del mismo Monasterio el manuscrito al que hago referencia y es el primer documento que analizo, está todo él publicado en el libro que, patrocinado por el CSIC, publicaron los catedráticos C. Viñas y $\mathrm{R}$. $\mathrm{Paz}^{10}$ y recogen las declaraciones efectuadas en Casarrubios por personas del lugar.

El libro de Vidal Benito lo toma todo de este documento. Tomo del mismo la última parte donde nos describe Casarrubios: «La villa de Casarrubios, de don Francisco Chacón, siete leguas de Toledo, es de setecientos vecinos poco más o menos, dicen haberse llamado de este nombre por dos hermanos que la comenzaron a poblar, que llamaron los Rubios, desde donde se dijo al principio las Casas de los Rubios, y adelante Casarrubios del Monte por ser la tierra de muchos montes. Pasa por la parte oriente el río de Guadarrama, que no lleva mucho agua, hay en el pueblo huertas muy buenas de buena hortaliza, regada con norias y olivares y arboledas. La población va en crecimiento. Hay dos hospitales, el uno que dicen de Corpus Chisti, y a él incorporados tres cofradías y el llamado de la Caridad, que lo fundo Pero del Castillo, hijodalgo y alcalde mayor de esta villa, para habitación de mujeres pobres de la dicha villa, que tiene de renta doce mil varavedíes. Es pueblo pasajero de Portugal y la Extremadura. Hay en esta villa un mercado franco, que se hace cada jueves en la semana, franqueado por los Reyes Católicos, y el que viniere a el es libre, que no puede ser preso ni molestado... ninguna deuda hasta ser vuelto a su casa» ${ }^{11}$.

Referente a la villa de «Casarrubios del Monte ejerció como delegado el párroco don Gaspar de Arévalo», quien solicitó las respuestas de tres ancianos de la villa, lo que demuestra unas respuestas equilibradas:

9 Benito Revuelta, Salamanca, o. c., 9-10.

10 C. VIÑAS y R. PAZ, o. c., 255-267.

11 Ibid., 35. 


\begin{abstract}
«Relación conforme a los capítulos que se pide a esta villa de Casarrubios por mandato del muy ilustre señor el licenciado Busto de Villegas, gobernador y general administrador del arzobispado de Toledo, la cual hice yo Gaspar de Arévalo, cura propio de esta villa de Casarrubios, y la hice hacer por personas que mas supiesen de ello, que fue a los diez de hebrero de mil y quinientos y setenta y seis. Fueron las personas a quien se cometió que diesen esta relación Diego de Ortega y Pedro de Rojas y Nicolás Delgado» ${ }^{12}$.
\end{abstract}

Los tres elegidos eran ancianos; al parecer, de buena memoria, ya que aducen un chorro de datos vigentes en la tradición oral.

La pregunta 38 solicitó recordaran «las personas señaladas en letras o armas, o en otras cosas buenas o malas que haya el dicho pueblo, o hayan nascido o salido de él, con lo que se supiese de sus hechos o dichos, y otros cuentos graciosos que en el dicho pueblo haya habido. «A la treinta y ocho, ha avido muchos ombres de armas, así de acaballo como de a pie que han hecho buenos hechos fuera de estos reynos, [...] pero refierese de algunos hombres principales que por letras y por la Iglesia han subido y se han señalado entre los cuales tratando de los muertos, que ha poco tiempo que murieron» ${ }^{13}$.

\title{
3.4. Casarrubios del Monte (Toledo)
}

Destacamos de Casarrubios que fue cercada esta villa, y está en pie gran parte de la cerca, fuera de la cual está una fortaleza, de cuatro torres de ladrillo a las esquinas, y a una redonda una cava honda, donde pone alcaide el señor de la dicha villa.

Beben en el pueblo de tres fuentes que hay en la villa, y de muchos pozos de buen agua. Van a moler a los molinos de la ribera del dicho río de Guadarrama y a los de Arroyo de Molinos y a los molinos del río Tajo. La leña que se gasta es de sarmientos y el despojo de los olivares y arboledas, y lo más de lo que traen a vender de la tierra de Segovia que es encina.

Fueron naturales de esta villa las personas contenidas en el capítulo 56. Es del arciprestazgo de Canales, hay dos iglesias parroquiales: «San Andrés fuera de la villa, la cual se llama la iglesia vieja, hay seis capillas, entre las cuales hay una de estos enterrado González Sánchez, escribano de cámara de su Magestad y también otras muchas capellanías y memorias, que la mayor de ellas llega a valer veinte y cinco mil maravedíes, el edificio curado de la iglesia valdrá tres mil ducados con dos beneficios servidores, que están enexados el uno al colegio de Santa Cathalina de Toledo, y el otro al monasterio y monjas de

\footnotetext{
12 Ibid., 255.

13 Ibid., 258.
}

Hispania Sacra, Estudios de Edad Moderna, 58

117, enero-junio 2006, 69-100, ISSN: 0018-215-X 
San Juan de la Penitencia de la dicha villa, y tiene por anexos esta iglesia parrochial del lugar de Villamanta, de doscientos y cincuenta vecinos, y el Alamo, ciento cincuenta, y el lugar de Valmujado, de ciento y treinta, y el lugar de las Ventas de Cabeza Retamosa, de ciento, y a la villa de la Cabeza, ciento y cincuenta vecinos.

Hay dos ermitas: una de San Sebastián. Es pueblo pasajero de Portugal y la Extremadura. Hay en esta villa un mercado franco, que se hace cada jueves en la semana, franqueado por los Reyes Católicos, y el que viniere a el es libre, que no puede ser preso ni molestado... ninguna deuda hasta ser vuelto a su casa» ${ }^{14}$.

\subsection{Juan de Dios y Casarrubios del Monte}

Estas Relaciones hacen una relación amplia: «Los licenciados Córdoba, Gómez del Rincón, Francisco Núñez..., médicos, humanistas, escritores, abogados, oidores, consejos de Castilla. Alumnos notables, a fe mía.

Entre hombres del bien o de la santidad citan a Garci Ximénez y Rodrigo de Vivar que distribuyeron sus rentas entre obras benéficas hasta morir pobres; el jesuita Juan Bautista, el fraile Gregorio Téllez, una monja María Evangelista; y el santo Simón de Rojas, confesor de Felipe II: no fue «natural» de Casarrubios pero acudió a consolar al rey que de camino cayó aquí retenido por enfermedad varios meses.

Llegando al dato que nos ocupa la relación termina «tratando de los muertos que a poco murieron», y cuyo recuerdo cierra esta línea sorprendente que queda para un análisis serio, profundo y delicado como es el tema y para la historia:

\section{- Iten Juan de Dios el que fundó el hospital famoso de Granada ${ }^{15}$.}

Así de claro es el documento, la noticia es escueta y terminante. Pero debemos señalar que «durante su vida en Casarrubios y en Oropesa» no se señala por nada digno de consignarse en las relaciones. La fama surge y se extiende a raíz del primer hospital que funda en Granada (1535), y por ello se hacen eco los de Casarrubios, y en su memoria vive el nombre de Juan de Dios veinticinco años después de su muerte. Y hay que tener en cuenta que en el mismo pueblo de Casarrubios abundan por aquel entonces los ejemplos de personas de allí naturales que fundan hospitales, colegios y capillas y en la propia localidad o en la de los alrededores y que vivieron gastando en pobres su renta ${ }^{16}$.

14 Ibid., 35

15 C. VIÑas y R. PAZ, o. c., 221v.

16 Benito Revuelta, o. c., 9. 
Ni Juan de Dios ni el hospital habían pasado desapercibidos, habían calado muy profundamente en el recuerdo del pueblo y en España «y para aquellos contemporáneos, el famoso hospital de Granada no era un hecho tan insólito que les llevara a recabar para su villa naturaleza de un hombre virtuoso y ejemplar (no olvidemos que entonces era todavía simplemente Juan de Dios, pues el proceso de beatificación comenzó hacia el 1622) de no haber sido verdaderamente natural de ella, ya que entre sus convecinos contaban con personas de más relieve social e intelectual que practicaban en alto grado la virtud de la caridad.

Por consiguiente, parece que no cabe dudar que San Juan de Dios, nació en Casarrubios, Toledo, en España» ${ }^{17}$.

No podemos ignorar una investigación seria de la mano de Vidal Benito Revuelta, que publica un librito de treinta páginas de la serie de «Temas Españoles», dedicado a San Juan de Dios. Dice de ello el P. Javierre: Su folleto alzó al aire otro enigma referente $a$ nuestro santo: una noticia sobre Casarrubios del Monte (Toledo) tomada del censo que mandó realizar el rey Felipe II el año 1575.

Entre los hombres del bien o de la santidad citan los que hoy viven: «Fue natural desta villa el licenciado Orozco, fijodalgo, canónigo de Murcia, inquisidor de la ciubdad de Toledo y arzobispo, y inquisidor general en el reino de Sicilia, y arzobispo de Palermo en el dicho reino. El protonotario Garci Ximenez, que poseyó este beneficio curado de Casarrubios cincuenta años, el beneficio de Navalcarnero destas diócesis, y el beneficio curado de Villa de Pera, que tuvo tres mil ducados de renta, que aunque no fue natural desta villa, sino de la ciubdad de Toledo, residió en esta villa estos cincuenta años haciendo buenas obras, gastando en pobres su renta» ${ }^{18}$. Otro tanto señala: «Hobo aquí por beneficio desta iglesia en el mismo tiempo al Doctor Rodrigo de Vivar, que fue hijosdalgo y del consejo de Fray Francisco Ximenez, provisor en el obispado de Zamora». Señalan sus rentas, lo mucho que hizo en favor de los pobres estudiantes, «sustentando una casa para doncellas honradas recogidas, no fue natural de esta villa, pero cuentase por el tiempo que fue beneficiado y residió en ella».

Prosigue: «Fue natural desta villa el inquisidor Lucero el famoso, fue natural el maestro Rincón, canónigo de Valladolid, iten el doctor Juan Bautista, segundo cura del lugar de Navalcarnero, tuvo dos mil ducados de renta, fue beneficiado en esta iglesia y cura de la villa de Borox, entró en la Compañía del nombre de Jesús en Roma, y dexo su renta, y fundó la casa de la Compañía en Navalcarnero anexándolo el dicho beneficio, que vale mil y quinientos ducados,

\footnotetext{
17 Ibid., 9-10.

18 C. VIÑAS y R. PAZ, o. c., 259.
} 
fue capellán de la Princesa de Portugal en este reino; iten el licenciado Francisco López vicario en la ciubdad de Toledo y en la villa y corte de Alcalá, y vicario y visitador de ciubdad Real, cura de las Ventas de Peña Aguilera. Iten el licenciado Rojas Carvajal, abogado, hijodalgo, tuvo algunos gobiernos en este reino. Iten el licenciado Córdoba, medico en Alcántara bueno».

Concluye este párrafo, «hobo otros muchos que están muertos, letrados, y los que viven» ${ }^{19}$. «Así, en seco; negro sobre blanco» escribe Javierre ${ }^{20}$. En el libro, citado de C. Viñas-R. Paz, y en Vidal Benito Revuelta, se encuentra claramente descrito, parece que no ofrece duda este dato del nacimiento de Juan de Dios. Es un documento muy significativo. Es un documento civil, no es de la Orden. Se realiza y cita circunstancialmente y con veracidad, no se ve ninguna intencionalidad marcada, está dentro de un contexto general y no dan amplias informaciones, sino que lo citan con toda su normalidad y sin ningún contexto especial. Es serio. Se debe profundizar en ello y no echarlo en el olvido.

El documento está ahí, en el día de hoy no hay otro. Este documento «se escribía en contestación a un cuestionario de interrogaciones ordenadas por el meticuloso Felipe II. La relación se hace por tres cualificados vecinos naturales de la villa, ante el párroco de la misma y sólo a veintiséis años después de la muerte de San Juan de Dios. Hay que pensar que estaban en lo cierto, además por otras consideraciones que después se harán, porque cuando hacen mención de otras personas de relieve que no fueron naturales del pueblo, pero que en él residieron, así lo hacen constar, como, por ejemplo, al dar el nombre del protonotario Garci Ximénez, del que dicen: «...que aunque no fue natural desta villa, sino de la ciudad de Toledo, residió en esta villa estos cincuenta años...» ${ }^{21}$.

El documento tiene su importancia y sería interesante un estudio minucioso, histórico, incluso si es preciso por una comisión de profesores y expertos que concreten y den su parecer final, ajenos a la Orden, para delimitar de una vez por todas, el tema ${ }^{22}$.

Por consiguiente, parece que no cabe dudar que San Juan de Dios, nació en Casarrubios, Toledo, en España, en el siglo XV.

19 Ibid., 259.

20 JAVIERRE, o. c., 137.

21 Benito Revuelta, o. c., 9.

22 José María JAVIERRE, o. c., 137-138: «Cuidado con la tentación de tomar a la ligera estas palabras del cura don Gaspar y sus tres viejecitos: hablan a sólo veinticinco años de la muerte del santo. Quien por cierto, Juan de Dios todavía no es famoso fuera de Granada: es famoso su hospital. ¿Por qué los de Casarrubios echan mano de su nombre, si es que lo roban, en vez de robar otro santo cualquiera? Mi conciencia de hurón historiador me obliga a tomarles en serio. Aunque lo adivino: estoy entrando en un laberinto». 


\section{SAN JuAn DE Dios SEgún SU PRIMER BIÓGRAFo Francisco De CASTRO}

Según el primer biógrafo, San Juan de Dios nace en el año 1495. Desde el primer momento de su existencia nos encontramos con el misterio de su nacimiento y primeros años de su vida. Castro, su primer biógrafo, no cita el año de su nacimiento, ni el nombre de sus padres, ni los apellidos de Juan de Dios; el tercer biógrafo, Govea, inventa el apellido de Ciudad, no sé de dónde lo saca, pero es incapaz ya en 1624 de decir el nombre de la madre que otro autor se lo inventa posteriormente. Es cuando aparece el famoso clérigo sin que lo sepan sus padres se lo lleva de su lado. Más misterio aún. ¿Por qué todo esto no lo esclareció su primer biógrafo, el serio, conciso y certero sacerdote Francisco de Castro? ¿Por qué se lo calló? Él tenía pruebas y datos todos recientes en el tiempo y en la época. Hoy nos hubiera evitado tantas preguntas al conocer el anterior documento.

Francisco de Castro era un sacerdote a quien el arzobispo Méndez Salvatierra, prelado de la diócesis de Granada desde febrero de 1578, nombró «rector» del hospital de Juan de Dios, que fue ampliando como herencia de su fundador y primer Rector de su Hospital, nuestro Juan Ciudad, como luego veremos.

Castro, que escribe la primera biografía de Juan de Dios y santas obras de su hospital, encargado por el citado arzobispo de Salvatierra, poseía una preparación intelectual propia de un «maestro» de la época, posiblemente graduado en teología. En un informe sobre el hospital de Granada que envía el arzobispo de Granada al Consejo de S. M., y que se encuentra en la Biblioteca Nacional de Madrid, describe muy bien el oficio del capellán del hospital: El oficio de Rector, que está dispuesto en las constituciones, título 6, y dice: «El Cura, a cuyo cargo está administrar los sacramentos a los enfermos pobres, a los hermanos y a los sirvientes. No basta uno para esto es necesario darle otro y otros compañeros Sacerdotes» ${ }^{23}$.

Castro acompañó a los primeros 24 hermanos que servían en el hospital. Se contagió del servicio, de la entrega y del cariño de los Hermanos y, por eso, escribió la primera biografía.

Esta biografía de Juan de Dios describe así su nacimiento: «El cual fue de nación portuguesa de un pueblo llamado Montemayor el Nuevo, que es en el obispado de Évora en el reino de Portugal, nació de padres medianos, no ricos ni pobres del todo, Criose con sus padres hasta la edad de ocho años, y de allí sin saberlo ellos, fue llevado por un clérigo a la villa de Oropesa donde vivió mucho tiempo en casa de un buen hombre llamado el Mayoral» ${ }^{24}$.

\footnotetext{
${ }^{23}$ Biblioteca Nacional. Madrid. Ms. N. ${ }^{\circ}$ Sig. 6948, f. 338.

${ }^{24}$ Castro, o. c., 4.
} 
En la Vida del Maestro Juan de Ávila, escrita por Fr. Luis de Granada nos dejará escrito al hablar de Juan de Dios; que Castro ha escrito una buena biografía sobre Juan de Dios y bien acentuado y descrito nos lo recuerda:

«Al fin de todos estos llamamientos, pondré el de Juan de Dios, del cual había mucho que decir sino estuviera escrita su vida, y bien escrita». Tomo de ella para seguir diciendo: Este hermano fue de nación portugués, natural de Monte Mayor el Nuevo. Y fue mucho tiempo pastor de ganado, y después soldado, y al fin trabajador. Venido a Granada y oyendo un sermón al P. Ávila, día de San Sebastián, de tal manera le tocó nuestro Señor, y de tal manera le hirió su corazón, que hizo tan grandes extremos que todos le juzgaron por loco; pero no creo que lo era por la razón que diré. Para lo cual es de saber que hay dos maneras de contrición y dolor de pecados: una común y ordinaria, y otra extraordinaria, cual fue la de la Magdalena, que entró en medio del día al tiempo que el Salvador estaba comiendo con sus discípulos, y otros convidados, sin hacer caso de tales cosas como había allí que mirar, porque la violencia del dolor cerró los ojos á todo esto. Y en la vida de nuestro Padre San Vicente Ferrer se escribe, que predicando él con aquel grande espíritu que el Señor le había dado, hubo hombres que heridos con la fuerza de sus palabras, daban voces en presencia del pueblo, confesando sus pecados. Y en el capítulo V de San Juan Clímaco, en que trata de la penitencia, cuenta cosas espantosas de las penitencias de aquellos monjes.

Y por esto no me escandalizan estos extremos que se vieron en Juan de Dios, mayormente significándose después de esto una tan grande santidad, como fue la de su vida, testificada con la solemnidad admirable con que toda la ciudad de Granada y todas las Ordenes se juntaron a celebrar su enterramiento. Pues como el principio de la conversión de este hermano fue por la doctrina del P. Ávila, así también lo fue el proceso de su vida, en la cual veremos a la letra cumplido lo que el Apóstol dice, 1. Cor. 1, que escoge Dios los estropajos y heces del mundo para hacer obras muy grandes, como lo vemos en este hermano; el cual quiso nuestro Señor que habiendo sido pastor, y trabajador, y soldado, fuera autor de una nueva religión para remedio de enfermos y pobres, que se va cada día extendiendo por el mundo, confirmada ya por autoridad de la Santa Sede Apostólica» ${ }^{25}$.

José María Javierre, con motivo del V Centenario del Nacimiento de Juan de Dios, ha escrito una magnífica biografía amplia, seria, ágil y que ambienta la época del santo, pormenorizando en varios datos históricos de personajes, momento social, político, religioso en que vivió Juan Ciudad.

25 Fr. Luis DE GranadA, Vida del beato Juan de Avila, Vergara, 1994, Parte II, cap. VIII, 146-146. 


\section{OPINIONES DE OTROS AUTORES}

Recientemente el P. Joaquín Sánchez ha escrito: «Aquel hombre, que viera su primera luz en el pueblo toledano de Casarrubios del Monte, tiene la convicción de que ha nacido para servir y no para mandar» ${ }^{26}$.

El P. Rafael Saucedo, uno de los hijos insignes de la Orden Hospitalaria, gran investigador, serio y preciso, que ha escrito en la revista Paz y Caridad «Ensayos Históricos. La Cronología aplicada en la Vida de N. P. S. Juan de Dios», en varios capítulos y que aclaran y precisan datos que Castro no tuvo la oportunidad de verificar ni al alcance de la mano como hoy los tenemos, nos ha legado estas precisiones que yo tomaré como referencia. Varias veces hablé con él sobre el nacimiento de Juan de Dios. Él lo tenía claro, me dijo, pero no era su momento, muchas veces ciertos acontecimientos tiene que madurarlos la historia. Yo espero que así sea.

En esta Cronología escribe: «Si para establecer una Cronología cierta en la vida del Santo nos contentásemos con recurrir a las fuentes tradicionales, esto es, a los Procesos de Canonización y a las vidas escritas por los autores más antiguos: Castro, Celi, Govea, Santos, Trinchería, por no citar más autores que los españoles, ya que los extranjeros no tienen fuentes propias y dependen en absoluto de los nuestros, cuando no sueltan los vuelos de la fantasía y se alzan a volar por los campos de la propia inventiva, la Cronología resultante sería forzosamente pobre y mezquina. Tendríamos a lo más, media docena de fechas fijas: el nacimiento del Santo en 1495; el viaje a Oropesa, a la edad de ocho años, y por lo tanto en 1503; el recibo de los cuatro ducados firmado por el santo, en Granada, el 6 de diciembre de 1548, que se conserva ahora en la capilla del Sr. Obispo de Córdoba; y la muerte del santo, el 8 de marzo de 1550. Total, cinco fechas ciertas; las demás están todas confusas, imprecisas o ignoradas cuando no abiertamente equivocadas. Lo cual nada tiene de extraño, si se tiene en cuenta que los testigos que deponen en el Proceso de Canonización y habían conocido al santo y presenciado los hechos de su vida, eran personas ancianas de 80, 90 y de 110 años; edad en que flaquea la memoria para los detalles y circunstancias, aunque retenga bien lo substancial de los hechos. Sus declaraciones en este punto concreto del tiempo en que sucedió tal o cual episodio han de ser forzosamente imprecisas. Se limitan a decir: «habrá unos setenta años; habrá más de setenta años»; «cuando era mochacho». Son fórmulas vagas que nada sirven para nuestro intento ${ }^{27}$.

Al analizar las vidas escritas sobre el santo, se aprecian los errores cronológicos existentes, no se corrigen y van pasando de generación en generación, de

\footnotetext{
26 Joaquín SÁNCHEZ, en Revista de Espiritualidad, 49 (1990), 229.

27 Rafael SAuCEDo, Cronología Hospitalaria, en Paz y Caridad, 1951, 336-337.
} 
los libros antiguos a los modernos, sin someterlos previamente a examen crítico. Este es uno de los detalles que quiero señalar, la verificación y aportación de estos datos y documentos. Pongo un ejemplo: sabíamos de la entrevista de Juan Ciudad con Felipe II, pero nunca lo que de ella se trató, nadie lo había comprobado. Investigando y verificando datos he encontrado cinco memoriales que presentó el santo al Rey Felipe y que hoy son inéditos para la historia después de tantos años.

«Una historia sin cronología, dice el insigne P. Florez en su España Sagrada, sería una cosa confusa; un palacio de grande ámbito, pero sin ventanas por donde entre la luz, en que todo será confusión y tropiezos». Y recordando a Bacon en el símil que emplea, quien llama a la Geografía y a la Cronología «los ojos de la Historia» ${ }^{28}$.

Todos los biógrafos del santo están de acuerdo en que nació en 1495. El año, pues, del nacimiento del Santo no ofrece duda. Unos dicen que nació el 8 de marzo; otros que el 25 del mismo mes. Ni unos ni otros tienen fundamento alguno documental histórico que permita fijar fecha determinada.

Cuando el año 1623, a instancias del P. Domingo de Mendoza ${ }^{29}$, juez de la causa de beatificación de Juan de Dios, el Arzobispo de Évora, D. José de Melo, instruyó el proceso en su diócesis, se buscó en Montemor o Novo la partida de bautismo del santo, pero como los libros parroquiales no comenzaban hasta 1542, no pudo hallarse este interesantísimo documento, que hubiese arrojado mucha luz no solo para la Cronología, sino también para la genealogía del Santo.

Al no hallar lo que se buscaba, el escribano eclesiástico de Évora, Juan Bautista Viegas, expidió este certificado: «Fui a la iglesia matriz de Santa María del Obispado de esta villa, y allí en el armario archivo donde estaban los libros de los bautizados en dicha Iglesia, los examiné todos, y el más antiguo era de 1542 , de hace 85 años por lo que no busqué más edad, ni el bautismo, por tener informes de que el nacimiento del santo Juan de Dios, es anterior con mucho, y no se conservan en dicha iglesia otros libros más antiguos».

Tenemos aquí una laguna, que nunca podremos llenar con datos fidedignos» ${ }^{30}$.

28 Ibid., 338.

29 Cf. Biblioteca Nacional, Madrid, Signatura: Ms. 7518, p. 2. Es un documento manuscrito que contiene las informaciones originales que se hicieron por autoridad ordinaria en la villa de Montemayor patria del bienaventurado p. Juan de Dios fundador de su Orden y de la hospitalidad de su santidad vida y fama y milagros en el Reino de Portugal, arzobispado de Evora, 1622 y 1623 . Vicario Ioan Pardín Frois, escribano eclesiástico Ioan Bautista Viegas, p. 1, son 66 páginas, casi todo él está en portugués con preguntas y respuestas del proceso. Es sumamente interesante todo él.

${ }^{30}$ Ibid., 137. 


\section{JuAn CiUdAd En Oropesa. Toledo}

Del primer periodo de la vida del niño Juan Ciudad, no sabemos nada más en la cronología de su vida ni para la Historia, hasta el misterioso retorno a España, a la edad de ocho años, que señala Castro en el Cap. 1, esto es, hacia 1503, regresa a España de donde lo llevaron. En esta fecha hay conformidad en los biógrafos. Corría el año 1503 y acaece un suceso singular: «y de allí sin sabello ellos fue llevado por un clérigo a la villa de Oropesa, donde vivió mucho tiempo en casa de un buen hombre llamado Mayoral» ${ }^{31}$.

El P. Javierre señala: «Que el hecho ocurrió resulta indudable, certificado por D. Francisco Castro, único guía a quien reconocemos como válido... pues he llegado a la conclusión de que Castro nos engaña en el primer párrafo de su obra... nos despista: queriendo; intencionadamente. Conozco la gravedad de esta suposición mía: hacer responsable a Castro de una fechoría histórica, puede significar atrevimiento excesivo... Castro nos desorientó, nos despistó. Desde luego, a él se debe la niebla... He aquí las líneas de Castro: «Criose (Juan de Dios) con sus padres hasta la edad de ocho años, y de allí, sin sabello ellos, fue llevado por un clérigo a la villa de Oropesa» ${ }^{32}$.

Como suena, el clérigo raptó un niño de ocho años, llamado João: lo raptó, pues lo saca de Montemor sin saberlo ellos, sin conocimiento y por tanto sin autorización de sus padres... que atrevido y responsable el señor clérigo. Este crío raptado no volverá por su pueblo como veremos hasta pasados treinta años. Sigamos: Aquí puede estar la clave del misterio del lugar del nacimiento. Es una frase que queda abierta y para estudiarla bien. Pero hay verbos que son todo un contenido contradictorio. Sospecho, con fundamento, que Castro conocía la respuesta puntual a estos interrogantes. La clave está en, «sin sabello ellos... lo sacaron ${ }^{33}$. No hubo acuerdo con los padres. Hay varias hipótesis sobre el clérigo, y ningún historiador serio digiere hoy el rapto del niño João tal como Castro lo cuenta: auténtico «nublado artificial» ${ }^{34}$.

Analizados los hechos de su nacimiento con los pocos datos que disponemos y sus fuentes, yo me pregunto y nadie lo ha hecho hasta hoy si el traslado que menciona Castro fue verdaderamente desde Montemor de Portugal o de Casarrubios del Monte, no repugna históricamente, quizá fuese lo más normal en aquel momento histórico que vivía España tan presionada por la Inquisición y solo el saber que era hijo de judíos, podría encontrar tantas dificultades en el Proceso de Beatificación, tal vez fuera esta causa la que estaba en el fondo de sus orígenes. Debemos verlo con criterios históricos no de nacionalismos, y si

\footnotetext{
31 CAStro, cap. 1, 1v.

32 Ibid., 1.

33 Ibid., 1.

34 JAVIERRE, O. C., 105-107.
}

Hispania Sacra, Estudios de Edad Moderna, 58

117, enero-junio 2006, 69-100, ISSN: 0018-215-X 
verdaderamente lo hacemos así con criterios históricos llegaremos sin dificultad a conocer que Juan de Dios nació en Casarrubios del Monte (Toledo) y no en Montemor el Nuevo como en tantos años se nos ha venido informando equivocadamente.

A la hora de redactar su biografía, Castro conocía perfectamente la verdad familiar del niño João: quiénes fueron su padre y su madre, cuál su origen, las condiciones económicas del hogar; desde luego, conocía el desarrollo y las motivaciones de la huida del niño. Castro en su proemio «al cristiano lector» avisa que como fuente «principal» de su trabajo utiliza un borrador que le dexó un compañero suyo... este compañero cuenta: lo que se le acordaba como testigo de vista» ${ }^{35}$.

Nos situamos «de nuevo frente a este «cuadernillo» y lo muy original que sería hoy para nosotros, principalmente la información familiar, pero Castro la esquivó. El manto de niebla resultó tan eficaz que a lo largo de cuatro siglos y pico de aparecer su libro, impreso en 1585, nadie ha conseguido descifrar el enigma» ${ }^{36}$.

Aquí sigue el misterio del silencio de la vida de Juan en Oropesa. Intentar llenar estos datos de su vida ${ }^{37}$, infantil y juvenil, apenas tenemos datos de estos veinte años, de lo poco que se sabe de este tiempo, todos los biógrafos nos dicen que los pasó el Santo ocupado en las faenas del campo, de la monótona vida pastoril, los cuales sabemos con certeza gracias a Castro: «que trabajó en el oficio de zagal y de pastor y era querido de todos» ${ }^{38}$, sirviendo en casa de los Herruz de Navas ${ }^{39}$ Francisco Vázquez, «el de las buenas memorias, mayordomo que fue del Conde de Oropesa, D. Fernando de Toledo, y en casa de Francisco Mayoral» ${ }^{40}$. «Trabajó con aplauso: de una parte, él, Juan «como le faltaron los padres en tan tierna edad» ${ }^{41}$, puso esmero en ganar la confianza de sus amos: «Servía con toda diligencia, todo el tiempo que en su casa estuvo» ${ }^{42}$. Por la otra, los amos, el reconocimiento al buen hacer del muchacho ${ }^{43}$.

35 Ibid., 115.

36 Ibid., 116.

37 Ibid., o. c.: «Los biógrafos procuran rellenar a fuerza de imaginación este vacío; pues aseguro a ustedes que da gran vergüenza contar la vida de un personaje y encontrarte con veinte años en blanco. De momento, veinte: volverá de nuevo a Oropesa para un trayecto de nueve años más. Total, veintinueve años», 116.

38 CAstro, o. C., 2.

39 Manuel Gómez Moreno, Primicias Históricas, Madrid, 1950, 195-198, Proceso de Beatificación de Oropesa, testigos: 5, 7, 8 y 9 .

40 SaUCEdo, O. C., 338.

41 Castro, o. C., 2.

42 Ibid., 2.

43 JAVIERRE, O. C., 162. 
Hago un paréntesis. Al preparar este trabajo, he leído en un documento de la Orden, que dicho «cuadernillo» fue utilizado por un General de la Orden, se conservaba en perfecto estado, en el siglo pasado. He intentado localizarlo, pero por la dispersión de archivos, no he conseguido la localización del mismo, es posible que se conserve, quizá mal colocado y no en su lugar como sería lógico. Estemos atentos a cualquier sorpresa agradable, al estar ahora en muchos archivos clasificando e inventariando los mismos.

El P. Saucedo, hablando un día sobre este pasaje del casamiento de Juan, me hacía esta reflexión muy sagaz y certera, me decía: «Conociendo la sicología y la forma de ser y actuar de entonces, de aquellas gentes, sabiendo la importancia de la posición social, un padre y más conociendo a los toledanos jamás propondría a su hija en casamiento con el pastor, era una contradicción, una humillación, quizá... poca cosa para las aspiraciones de todos los padres, como es casar a sus hijas con personas de dinero y de más alta categoría social o al menos y no menor que la suya, por orgullo personal y familiar». Y en este caso fue posible, la propuesta, ¿por qué? Me decía, ¿acaso Juan Ciudad fue hijo natural del Conde de Oropesa? Porque Juan Ciudad no era un cualquiera, era algo más. Y ese algo más... es Juan Ciudad, el hombre al que sigo investigando.

Al no disponer de datos, el misterio queda flotando, el tema es más escabroso, por lo tanto la situación es más oscura. Suposiciones quizá, pero ¿en qué fundadas? De lo que llevo visto deduzco una personalidad, singular, grande, no común en el entorno, Juan no era un haragán o cualquier joven agricultor, pastor de la estepa castellana; su personalidad era diferente, su educación por lo que fuese, también distinta, quede dentro del misterio de este proceso. Quizá algún día se encuentren más documentos, que nos puedan aclarar este misterio. Este Francisco Mayoral y Francisco Vázquez son dos personas diferentes, solamente que unos testigos los nombran por su apellido y otros por su oficio.

\section{LA SOCIEDAD A FINALES DEL SIGLO XV Y COMIENZOS DEL XVI}

Al final del siglo XV nos situamos en una sociedad con las mismas virtudes y pecados, ni mejor ni peor que la de hoy, distinta. Gobernaba la Iglesia el Papa Alejandro VI, sobrino de Calixto III, ambos españoles. Dirigían los destinos de los reinos de España los Reyes Católicos Isabel y Fernando, y en Portugal el rey D. Juan II, que murió en 1495.

El momento era de paz y su llegada a América en 1492, con Colón, se produce el encuentro de las dos culturas. Finalizada la conquista de Granada, termina el encuentro de otras tres culturas, España en el final del siglo XV y co-

Hispania Sacra, Estudios de Edad Moderna, 58

117, enero-junio 2006, 69-100, ISSN: 0018-215-X 
mienzos del XVI era una nación tranquila. Época de nacimiento de grandes santos: Santo Tomás de Villanueva, San Ignacio de Loyola, San Juan de Ávila, San Pedro de Alcántara, San Alonso de Orozco y San Juan de Dios.

Existe una curiosidad intelectual, una conciencia de la dignidad de su profesión, caridad para con los pobres y apasionado interés por los más diversos aspectos de la vida pública. Para evocarlos se aúnan las figuras señeras de todos ellos. Hombres generosos que lucharon contra los males de su época para corregirlos; esperan ayudar a sus semejantes, iluminarlos, socorrerlos y reformarlos. Ser una conciencia en medio de la crisis, el dolor, la ignorancia y la inoperancia. Renacer, redescubrir y vivificar los valores cristianos. Etapa de oro de la Iglesia en España.

\section{JUAN DE Dios, AMPARO DE LOS POBRES Y ENFERMOS EN GRANADA}

\subsection{La marginación en el siglo XVI}

Cuando comienza a ejercer la hospitalidad Juan de Dios en 1535, reina en España Carlos V, aunque la regencia está, propiamente, en manos de Felipe II. Tanto el uno como el otro, siempre se preocuparon y estuvieron muy atentos a la situación de los pobres y enfermos y procuraron realizar una reforma social sobre este tema. Se concretó en instituciones benéficas que, en forma de cofradías caritativas o instituciones hospitalarias, como las Compañías del Divino Amor ${ }^{44}$, y la Tercera Orden Regular Franciscana ${ }^{45}$, representaron en España con cierta fuerza una animación cristiana de grupos seglares. En tierras andaluzas y toledanas tuvieron gran arraigo las cofradías de la caridad, que, con sus refugios y hospitales de enfermos y mendigos, son un claro precedente de la de los hospitales de incurables y de las casas de Misericordia del siglo $\mathrm{XVI}^{46}$.

Durante el reinado del Emperador, creció extraordinariamente la sensibilidad hacia los problemas sociales más llamativos: los enfermos incurables que encontraron en Juan de Dios y sus compañeros, sus primeros campeones: Antón Martín, Pedro Velasco ${ }^{47}$; los niños abandonados que son acogidos y educa-

\footnotetext{
44 Ricardo García Villoslada, Historia de la Iglesia Católica, III, Madrid, 1960, pp. 582-3.

45 José García Otero, Galicia en los siglos XIV y XV, I, Santiago-La Coruña, 1987, pp. 215-252.

46 Ibid., Francisco de Asís en la España medieval, Santiago-Madrid, 1988, pp. 431-2; Ibid., La Iglesia de Toledo en tiempo del Cardenal Cisneros (1495-1517), Toledo, 1992, pp. 98-105.

47 José García Oro, M. ${ }^{\text {a }}$ José Portela Silva, «Felipe II y la reforma de las costumbres», en $L a$ Ciudad de Dios, 211 (1998), 1028; Noticia bio-bibliográfica en DHEE II, 1248-9.
} 
dos en las Casas de la Doctrina Cristiana ${ }^{48}$ y los colegios fundados por Fernando de Contreras, Juan de Ávila y la incipiente Compañía de Jesús ${ }^{49}$.

Estas iniciativas se prolongan en el reinado de Felipe II. Surgieron nobles valedores de estos proyectos como los duques de Sessa en sus estados ${ }^{50}$. En el gobieno temporal de prelados, como el Cardenal Cisneros, entraba este ideal de la beneficencia ${ }^{51}$. Más directamente apadrinan estas iniciativas los prelados que las ven nacer, como el arzobispo granadino D. Pedro Guerrero $(\dagger 1576)$ que se hizo cargo a la muerte del hospitalario de la obra de Juan de Dios $^{52}$.

Él fue de alguna manera, el puente que une los reinados de Carlos V y Felipe II en la línea de la sensibilidad social ${ }^{53}$.

El Concilio Tridentino había trabado muchos de estos problemas de la sociedad cristiana; insistía en todas las tareas, especialmente en el gobierno de los hospitales y en la acogida de los indigentes ${ }^{54}$. Los datos conocidos en la actualidad llevan a afirmar que el Concilio Tridentino significó un reto para Felipe II: reorganizar la vida eclesiástica y civil y, en lo que a nosotros concierne, la beneficencia especialmente a la acogida de los pobres y reorganización de los hospitales.

Felipe II en su reforma tiene en cuenta la Junta de Reformación que establecía los criterios y las iniciativas en este campo. Se le propone, por medio de memoriales, la solución de crear un procurador de los pobres en el Consejo Real ${ }^{55}$.

La España de Felipe II albergaba la antítesis del lujo y de la miseria. Los vestidos y el boato de las casas no tenían límites y embarcaban, inexorablemente, a los ciudadanos en una deuda sin fondo. No bastaban las sedas italianas ni lo tejidos de Flandes para cubrir la marea de ostentación que empujaba a los cortesanos. En consecuencia, los precios seguían disparados y mermadas las rentas sociales, que apenas podían cubrir la intendencia militar. Arrastraba lacras sociales clamorosas que se evidenciaban dramáticamente. Los desvalidos

48 Félix SANTOlaria SiERra, «Los colegios de doctrinos o de niños de la doctrina cristiana. Nuevos datos y fuentes documentales para su estudio», en Hispania, 192 (1996), pp. 267-290. Para el tema en su conjunto, véase la obra Historia de la acción educativa de la Iglesia en España, I, Madrid, 1995, dirigido por Bernabé Bartolomé, 267-290.

49 José García Oro, M. ${ }^{a}$ José Portela SiLVA, Felipe II y la reforma de las costumbres, 1028.

50 Octavio MARCos, «San Juan de Dios», en DHEE II, 1948-49.

51 José García Oro, La Iglesia de Toledo, Toledo, 1992, pp. 19-50.

52 Antonio MARÍn OCETE, El arzobispo don Pedro Guerrero y la política conciliar española en el siglo XVI, I-II, Madrid, 1970. De este prelado y reformador tridentino existe una sólida bibliografía debida fundamentalmente a este autor, el resultado de sus investigaciones se ofrece en la monografía.

53 José García Oro-M. a José Portela Silva, Felipe II y la reforma de las costumbres, 1028-9.

54 Concilio de Trento, Sesión VII, cap. 15 (marzo de 1547) y sesión XXV, cap. 8 (1563). Puede verse en Constancio GuTiÉRREZ, Españoles en Trento (Valladolid, 1951).

55 José García Oro-M. José Portela Silva, Felipe II y la reforma de las costumbres, 1038.

Hispania Sacra, Estudios de Edad Moderna, 58

117, enero-junio 2006, 69-100, ISSN: 0018-215-X 
de todo orden pululan por las calles exhibiendo su miseria: niños abandonados y enfermos, mendigos en manada que demandan la ayuda y la compasión callejera, mujeres de la vida que circulan sin control. El clamor para poner remedio a estas miserias lo representan las personalidades más comprometidas del período, Juan de Ávila con sus colegios y seminarios, los jesuitas, que prosiguen e institucionalizan la escolaridad benéfica, y los grandes abanderados de los pobres, como Juan de Dios y sus compañeros.

Siguiendo las iniciativas de los municipios flamencos, convertida en doctrina humanista por Luis Vives, el año 1540 se promulga por el regente, Cardenal Tavera $^{56}$, una ley de recogida de los pobres en el ámbito de los municipios; pretendía remediar su extrema indigencia proveniente, en buena parte, de las crisis agrícolas de los años 1538-153957. Esta normativa se fija, con especial cuidado, en los niños. Se vedaba su tradicional limosneo por las calles y se ordenaba su concentración en casas donde pudiesen ser «adoctrinados», curados, alimentados, alfabetizados y entregados a algún patrón fiable que los mantuviese en el servicio doméstico. Tuvo su efecto y las Cortes de Castilla de 1548 la refrendaban como solución eficaz ${ }^{58}$; las mismas harían otro tanto con los memoriales que Juan de Dios le presentó a Felipe II a favor de los pobres y del Hospital de Granada $^{59}$.

Es significativo este tiempo de coincidencia en el buen hacer en favor de los pobres: los municipios, los abanderados de las clases populares como el Maestro Ávila, los obispos más sencillos como el granadino arzobispo Guerrero, que llevan el tema al Concilio de Trento, para que el problema infantil tenga resonancia y reciba soluciones ${ }^{60}$.

El año 1540 sintió muy profundamente el problema de los pobres y suscitó normas en numerosas Ordenanzas de pobres en las ciudades, así como la discusión académica sobre la licitud de su encerramiento y asistencia, que implicaban el abandono de la mendicidad callejera. Felipe II heredó esta lacra social y la pudo palpar en la villa y corte de Madrid que, a principio de su reinado, era

56 R. GonZÁlvez, «Tavera o Pardo de Tavera Juan», en DHEE, IV, 2536. Juan Pardo Tavera, cardenal arzobispo de Toledo, nació el 16 de mayo de 1472 en Toro, Zamora, y murió en Valladolid el 1 de agosto de 1545. Fundó el Hospital de Afuera, o Tavera de San Juan Bautista, que comenzó en 15641, «al que dejó por heredero universal en su testamento. Allí está enterrado bajo la cúpula de la Iglesia en un magnífico sepulcro labrado por Alonso Berruguete, con bibliografía.

57 Félix SANTOlaria SierRa, «Los colegios de doctrinos o de niños de la Doctrina cristiana. Nuevos datos y fuentes documentales para su estudio», en Hispania, 56 (1996), 268-9.

58 Cortes de los antiguos Reinos de LeÓn y de CAStilla, publicadas por la Real Academia de la Historia, vol. V (Madrid, 1903).

59 José Luis MartíneZ, San Juan de Dios Fundador de la Fraternidad Hospitalaria, BAC, Madrid, 2002, AP, Memoriales, n. ${ }^{\circ}$ 2, 3, 4, 5, 6 .

60 José García Oro y M. ${ }^{a}$ José Portela Silva, Felipe II y la reforma de las costumbres, 1040-1. 
un hormiguero de mendigos. Apoyó por esta causa la labor comenzada por el H. ${ }^{\circ}$ Antón Martín, que había fundado en Madrid el Hospital de Nuestra Señora del Amor de Dios en 1552, a ejemplo del que fundó en Granada Juan de Dios; lo apoyó y ayudó tanto en limosnas como procurando bulas de los papas; después apoyó a los primeros Hermanos, seguidores de la labor humanitaria de Juan de Dios, la luz de la hospitalidad de Granada.

\subsection{Esclavitud y pobreza: enfermos y peregrinos en el Renacimiento}

En este tiempo uno de los males era la falta de trabajo, formación seria de las personas, hábitos de trabajo para los oficios diversos, por falta de medios económicos, lo que llevaba a una parte de la sociedad a navegar en la ociosidad. Con tanta gente ociosa, pululaban los vagamundos y salteadores; siendo frecuentes los adulterios sabidos y callados, la desverguienza de mujeres y la verdadera pobreza de gente así que abundaba en tantas ciudades españolas y europeas.

Existen fuertes singularidades que caracterizan la sociedad del siglo XVI. La primera y la más fuerte en sí misma y para nuestra sensibilidad actual, fue la esclavitud. Aquella sociedad, llamada cristiana, dio por bueno el hecho de tantos hombres privados de su libertad, los esclavos. Enfrente, los privilegiados por la ley empezando por el clero alto y la nobleza. La inmensa mayoría la componían el estado llano, lo constituían los pecheros; sobre ellos actuaba la opresión tributaria de la Hacienda ${ }^{61}$.

La sociedad del siglo XVI se caracteriza por fuertes contrastes sociales, algunos de los cuales vamos a mencionar. El primero y más fuerte, para nuestra sensibilidad formada en los derechos humanos, fue la permanencia y aumento de la esclavitud. Permanencia que continuaba vigente la teoría medieval que legitimaba la esclavitud, non a natura, sed paena pecati y por el derecho de guerra, a cambio de la muerte. Por otra parte, el medieval Corpus Iuris Canonici presenta la esclavitud como hecho social, aunque hace algunas precisiones sobre la libertad para recibir determinados sacramentos.

Las guerras con los árabes y las razias del Mediterráneo servían para aprovisionarse de esclavos, y pedir un rescate o condenarlos a remar en galeras. Las Órdenes religiosas, como los Mercedarios y Trinitarios, polarizados a la redención de cautivos, hunden sus raíces en la esclavitud y escribieron páginas gloriosas, en la historia de los siglos siguientes; recuérdese la «redención» de Miguel de Cervantes.

El problema de la esclavitud se agravó con los grandes descubrimientos de África y, sobre todo, de América. La necesidad de mano de obra hizo dar un

61 Manuel Fernández Álvarez, La sociedad española, Madrid, 1984, pp. 153-4. 
salto cualitativo a la visión medieval de la esclavitud mediante el comercio y asiento de negros, que fueron trasladados en masa a las nuevas tierras.

Otras notas reveladoras de la peculiar sociedad de este siglo, hay que verlas más desde el punto de vista cuantitativo que cualitativo. El segundo contraste era la mendicidad, las pavorosas dimensiones que había adquirido. Los pobres pululaban por todas partes, pidiendo en las calles, apostados en los lugares donde esperaban que la caridad fuera más generosa, como las puertas de las iglesias. Las festividades religiosas de los pueblos, las romerías, que atraían a los lugareños a las apartadas ermitas donde veneraban tal o cual figura del santo/a, eran otras tantas ocasiones para que se produjeran verdaderas concentraciones de mendigos. El problema era de tal calibre que los más altos pensadores de la época, recuérdese a Luis Vives, Francisco de Vitoria, Domingo Soto, Fray Juan Robles, Lorenzo de Villavicencio, Cristóbal Pérez de Herrera, entre otros, no dudaron en abordarlo para buscar soluciones.

Entre las clases privilegiadas, los esclavos y los mendigos, se puede comprender el tremendo contraste entre la riqueza de los poderosos y la miseria de los mendigos ${ }^{62}$. La clase media era muy exigua, frágil y endeble. El hampa ha sido una realidad de todas las sociedades y de todos los tiempos; en esta época, el Estado necesitaba del servicio de remeros para sus galeras y los sacaba de los condenados por la justicia. Con ello, la figura del galeote adquiere unos perfiles que sólo volveremos a encontrar en los proletarios de la sociedad pre-industrial del pasado siglo.

Las luchas contra los moros, fueron constantes fuentes de esclavos. Las Órdenes religiosas, los Mercedarios y los Trinitarios polarizadas en tales menesteres, la redención de cautivos, realizaron una labor tan liberadora como misericordiosa. Por otra parte, sectores tan importantes de la Iglesia, como las Órdenes mendicantes, y en particular los franciscanos, vivían entre el pueblo, se nutrían del pueblo y por ello sentían todos sus anhelos de justicia; de ahí que, en las conmociones populares, se vean tantos de sus representantes. Por ello la Iglesia - a pesar de sus privilegios - era popular, aunque no todos sus miembros estuviesen a la altura exigida ${ }^{63}$.

La Iglesia siempre ha tenido tareas sociales que ahora ha absorbido el Estado: Hospitales, Casas de expósitos y, en general, la Beneficencia y la Enseñanza. De forma que a la lista de Hospitales de fundación eclesiástica, pueden añadirse las Universidades y los Colegios Mayores: así los Hospitales de la Santa Cruz, fundado por el Cardenal Mendoza, en Toledo, o el que en la misma ciudad levantaría Tavera, y que aún lleva su nombre. Así la Universidad de Alcalá

62 Ibid., 154.

63 Antonio Domínguez, Las clases privilegiadas en la España del Antiguo Régimen, Madrid, 1973. 
de Henares, al crear el de San Ildefonso, por el cardenal Cisneros, donde brilla, espléndida, la portada de Covarrubias, con el águila bicéfala de Carlos V, y los Colegios Mayores de Anaya, Fonseca, Oviedo y Cuenca, en Salamanca, fundados respectivamente por esos prelados; lo mismo sucedió en Santiago. En Valladolid lo haría Mendoza, con el Colegio Mayor de Santa Cruz, la obra maestra de Lorenzo Vázquez ${ }^{64}$.

La asistencia siguió dependiendo, esencialmente, de la caridad privada. Ésta no desfallece, antes al contrario, se anima, y cobra nuevos impulsos. Hasta tal punto sigue siendo vigoroso el ideal tradicional: presenta al pobre como el intercesor privilegiado entre el creador y sus criaturas, como el que abre las puertas del reino. No resulta exagerado pretender que una parte considerable de la riqueza de la España del Siglo de Oro fue redistribuida a los pobres a través de una multitud de donaciones, legados y fundaciones ${ }^{65}$, comenzando por el Hospital que funda Juan de Dios, como los que siguieron fundando los primeros hermanos y sucesores del santo y los Hospitales de Granada.

Los españoles de aquella época se acordaban de los pobres, sobre todo en la hora de la muerte. Casi todas las personas que disponían de tiempo para redactar o dictar su testamento - caballeros, letrados, mercaderes, artesanos, labradores - destinaban unos legados a las instituciones que tenían a su cargo a los ancianos, a los enfermos, los miserables, los niños abandonados. En consecuencia, todos los Hospitales, o Casas de misericordia, recibían periódicamente el producto de estos legados, generalmente modestos (algunos maravedíes), a veces considerables, hasta llegar a varios centenares de reales, e incluso más. Algunos ricos, nobles, eclesiásticos y comerciantes, legaron verdaderas fortunas en forma de fundaciones de Hospitales, Cofradías o rentas destinadas a la distribución periódica de ayudas, en dinero o en especie: o bien, para la creación de dotes a favor de huérfanas pobres ${ }^{66}$. Veremos luego cómo Juan de Dios, y su Hospital, se beneficiaron de todo esto.

Pero la caridad no sólo se realizaba con limosnas. Algunos le dedicaban parte de su vida, como Don Miguel de Mañara, en Sevilla, que reanimó la famosa cofradía de la Caridad, en la que agrupó a una gran parte de la alta nobleza y de la más rica burguesía, y dedicó casi toda su actividad al socorro de los pobres. No obstante, la forma más habitual de la actividad caritativa era la participación en una cofradía de asistencia, bien tuviera ésta una base parroquial o una vocación precisa (niños abandonados, huérfanos, pobres, enfermos o impedidos). Unas tenían a su cargo un Hospital, o la asistencia de los encarcelados. Otras se

64 Ibid., 165.

65 José Luis Martínez, o. c., AP, n. ${ }^{\circ} 35$.

66 Bartolomé Bennassar, La España del Siglo de Oro, 217. 
interesaban por las mujeres arrepentidas, por la redención de cautivos, por la educación de los huérfanos, por la sepultura cristiana de los difuntos pobres, por los ciegos o por los sordomudos.

Las sumas destinadas de esta manera para las necesidades de caridad eran enormes. En numerosas ocasiones, la gestión era deficiente y las rentas de muchos Hospitales eran consumidas por el personal asalariado de los centros, que no se encontraban ya en condiciones de garantizar sus cuidados más que a un reducido número de pobres o de enfermos. El respeto de las instituciones producía parasitismo y traicionaba las voluntades de los fundadores. Se toma conciencia y se prepara la reducción de hospitales, como veremos ${ }^{67}$.

Se publican importantes obras literarias como el Lazarillo de Tormes, Amparo de pobres de Cristóbal Pérez de Herrera y del Guzmán de Alfarache de Mateo Alemán, Rinconete y Cortadillo de Cervantes, Deliberación por la causa de los pobres, de Domingo Soto, La Celestina, Viaje a Turquía, donde se analiza la situación del pobre y la picaresca de este siglo en muchos de sus pasajes que nos indican la situación por la que vivía España en el llamado Siglo de Oro. Existía en las grandes ciudades, Valladolid, Valencia, Toledo, Madrid, Córdoba, «una fauna parasitaria que vivía a expensas de los demás basándose en estafas, robos y asesinatos. En ninguna otra parte se había desarrollado tanto esta fauna, proliferaba tanto como en Sevilla y la descripción de la picaresca se nutre gustosamente de abundantes ejemplos sevillanos» ${ }^{68}$.

La diversidad social de los pícaros constituye un problema y los especialistas de la picaresca, evidentemente, no lo han eludido. El rechazo al trabajo es la consecuencia del prejuicio aristocrático: el pobre y el pícaro son las dos caras de la misma realidad. Al suscitar el mantenimiento del pauperismo y de la picaresca, el orgullo aristocrático enlaza, paradójicamente, con los caminos del ideal del evangelio ${ }^{69}$.

Juan de Dios, tras su conversión vivió una experiencia singular hospitalaria; primero en el Hospital Real de Granada, luego en el Monasterio de Guadalu$\mathrm{pe}^{70}$. Su experiencia no fue sólo teórica, sino práctica, y apostólica. Su pensamiento, a lo largo del retorno de esta peregrinación a Guadalupe, era el total convencimiento de su vocación en la entrega y servicio de caridad a los pobres y enfermos, especialmente a los más abandonados; por el camino iba pensando:

67 Ibid., 220.

68 Ibid., 221-2.

69 Ibid., 226.

70 F. Hironimo Roman, Osa, Repúblicas del Mundo, en Casa de Juan Fernández, Salamanca, 1595, «Entre las cosas notables que se han visto en nuestros tiempos en España es la santidad y vida del pobre Juan de Dios padre de los pobres y fundador de una Orden toda dedicada a la caridad del prójimo curando en los hospitales y remediando necesidades de todos los que las tienen para el cuerpo y también para el alma», cap. 34, 380v. 
serviré a «mis amos y señores», los enfermos, antes de que los indefensos de la vida se mueran abandonados por las calles de Granada. Aprendió, muy bien, no sólo la dimensión espiritual, sino todo lo referente a la formación profesional, por la asidua y diaria asistencia a la Escuela de Medicina y a la famosa Farmacia del monasterio de Guadalupe.

Primero reflexionó serenamente; luego pidió parecer sobre el estado y proceso de su vocación con el prior de Guadalupe, Fray Francisco de Santa María ${ }^{17}$. Comprendió, desde el primer momento, orientado por el P. Maestro Ávila, su mejor amigo y maestro espiritual, su decisión y vocación hospitalaria. El P. Ávila, que estaba abriendo escuelas y colegios, siempre haciendo el bien y ayudando a todos, vio en Juan de Dios, otra causa noble y grande: ayudar a la sociedad en una parcela muy singular, el mundo del dolor; los pobres y enfermos, indefensos, que tanto le habían cautivado en la ciudad de Granada.

El Maestro Ávila lo orientó en todos sus pasos al comienzo. Le recomendó a personas importantes, las que más podían ayudarle con limosnas para las obras que traía en manos y encaminarle en lo referente a donaciones y posibles ayudas para la casa que abrió en Granada con la ayuda de todos. Le aconsejó ponerse bajo la orientación del P. Portillo, que fue una ayuda singular y espiritual en el camino comenzado, para bien de su alma.

El P. Ávila no dudó un momento en apoyar y orientar a Juan de Dios tras su conversión. Afianzó su vocación en los cimientos evangélicos de humildad y anonadamiento para vivir el ministerio de la caridad. Juan, que le abrió su alma y siguió sus sabias orientaciones, en una transformación personal, quiere ahora, desde el hombre nuevo, renovar las estructuras sociales según los signos de los tiempos, unido con Cristo y en sintonía con la Iglesia; colaborar en la humanización de la marginación y pobreza. Este proceso lo realizó abierto a los designios de Dios, sirviendo, trabajando y entregando su vida a los pobres y necesidades de Granada.

Por indicación del Maestro Ávila, el P. Portillo será el segundo maestro que tanta trascendencia tendrá en la ayuda espiritual que le una a Dios; los dos, de mutuo acuerdo, ayudarán al santo, lo tendrán cerca, y podrán, en todo momento, ser su mejor ayuda.

Al comenzar una obra nueva siempre lleva multitud de incomprensiones, contrariedades, adversidades incomprensibles. En todos los comienzos hay inmensas dificultades y más en aquella época que todo estaba controlado y en

\footnotetext{
71 Luis Ortega, San Juan de Dios, «El prior entonces como consta de la serie de los priores de esta Santa Casa, el Rvdmo. P. e ilustrísimo Sr. D. Fray Francisco de Santa María, del linaje de los Benavides y Manrique, Marqueses de Frómista [en Palencia]. Fue el 31. ${ }^{\circ}$ Prior en Guadalupe, brilló en el Concilio de Trento llamado por el papa Julio III (1550-1555), y fue obispo de Cartagena de Indias, de Mondoñedo y de Segovia», 271.
} 
manos de los poderosos. Pero irrumpe en la historia y en Granada Juan de Dios, un laico, que vive como un cristiano normal con el solo caudal del carisma que Dios le ha dado, con un corazón misericordioso y lleno de caridad que recibe de Cristo.

No va a quedar ahí, lo vivirá y desarrollará en una ciudad recientemente conquistada y controlada por la Inquisición. Un laico sin otro pasaporte que la locura de su caridad, comienza abriendo un hospital, revolucionando la medicina con el ejemplo de su simple ministerio hospitalario, humanizando el ambiente y el trato con los enfermos.

Los inicios no tuvieron que ser fáciles. Comienza a poner en práctica lo que Dios le ha inspirado en su corazón: abrir un hospital para acoger y atender a todos los pobres enfermos que encuentra a su paso por la ciudad de Granada y los que busca por pueblos de la provincia, no necesitan más requisitos que la necesidad y la enfermedad. En el momento que abre su Hospital estará siempre abierto a todos los enfermos como nota distintiva y nueva en la ciudad, siempre abierto a la misericordia.

En España, como en otros países, se plantea a comienzos del XVI el problema de estos vagabundos. ¿Qué hacer con esta plaga de mendigos, que vivían de la caridad pública, a los que se mezclaban impostores, truhanes y hasta desertores de la milicia? ¿Cómo tratar a esta multitud, aquejada de miserias físicas y morales, maloliente y transmisora de enfermedades? Las Cortes Castellanas de $1518,1523,1528,1534,1544$, se preocupaban de este problema y de que se abrieran más Hospitales ${ }^{72}$.

Se intenta solucionar el conflicto dándoles a los adultos subsidios, a través de las parroquias o de cofradías religiosas, específicamente creadas para ello, que repartían pan y alimentos. En los casos de graves necesidades, que eran tantas, conventos, monasterios y obispos se encargaron de traer y de repartir públicamente trigo.

Tuvieron su papel importante los pequeños Hospitales, patrocinados por cofradías y Hermandades religiosas, que acogían a los enfermos abandonados. Estas cofradías estaban integradas por personas de toda condición social, incluso nobles, y tenían como finalidad la práctica de la caridad con enfermos, menesterosos y moribundos. Como ejemplo de esta humanitaria y cristiana labor, surge Juan de Dios, y luego sus Hermanos, con la Fraternidad Hospitalaria que pueblan España de pequeños y grandes Hospitales, dando solución a este inmenso problema, como veremos ${ }^{73}$.

72 V. VÁzQUEZ DE PRADA, Historia económica y social de España, III, Los Siglos XVI y XVII, Madrid, 1978, p. 256.

73 Ibid., 258-9. 
Lo normal era que, con frecuencia, estos pequeños hospitales y enfermerías estuviesen mal dotados, económica y materialmente, para proporcionar una asistencia eficaz. Ello era consecuencia de la dispersión de esfuerzos. Rara era la ciudad que no tenía 6, 8 y 12 hospitales, como Granada en tiempo de Juan de Dios, según veremos.

Juan de Dios conoce este ambiente. Lo vivió desde su ingreso en el Hospital Real de Granada. Luego, en su peregrinar a Guadalupe y en el mismo Monasterio. No olvidó su experiencia de Ceuta. Su corazón quiere hacer algo por ellos. No le había llegado su hora. Hoy diríamos que supo intuir y leer los signos de los tiempos y, cuando llegó la hora de dar respuesta al Señor, no lo dudó un momento y entregó toda su vida a este ministerio de caridad, abriendo Casas y Hospitales para dar acogida, medicina, limosnas y un mensaje del evangelio de la misericordia de Jesús.

\subsection{El concepto de hombre en Juan Ciudad}

¿Cuál era el pensamiento de Juan Ciudad, sobre los hombres? ¿Qué concepto se había formado de la vida? Se deduce de sus escritos que su pensamiento sobre los hombres, era sencillo, claro y profundo; que todos los hombres son hijos de Dios, hermanos entre sí por la común naturaleza, pero sobre todo por los lazos de la gracia que los hace miembros del cuerpo místico de Cristo; que estamos llamados a un destino inmortal; que las almas creadas por Dios y redimidas por la sangre de su Hijo no tienen su centro en la tierra sino en el Cielo, nuestro último fin. Por eso siente por los pobres esa singular ternura; se preocupa de las dolencias del cuerpo, pero anteponiendo la salud de su alma, porque lo único necesario es la salvación, por eso pregunta a los que llegan a su hospital, ¿habéis hecho confesión? Y la hoguera que enciende para todos ellos en medio de la casa, es simbólica; calienta los cuerpos del frío granadino, pero luego aprovecha para enseñarles el catecismo y la doctrina cristiana, y les recuerda los misterios de nuestra salvación. Esa es la misión de Juan de Dios: amar por Jesucristo a los pobres, los hombres enfermos, empezando su vida de apostolado desde el más profundo conocimiento y valoración del hombre, del hombre pobre y enfermo, en nombre del Señor Jesús.

\section{Hospitales en Granada en la ÉPOCA DE JuAN De Dios}

\subsection{Los hospitales de Granada atienden enfermos, peregrinos y pobres}

Nos vamos aproximando a la realidad asistencial en tiempos de Juan de Dios con mayor precisión, al disponer de nuevos documentos encontrados. José

Hispania Sacra, Estudios de Edad Moderna, 58

117, enero-junio 2006, 69-100, ISSN: 0018-215-X 
Cruset, nos dice: «Existen en estos momentos tan sólo dos Hospitales en Granada, el Real y el de Santa Ana, instituciones de tipo oficial, cuyas características en cuanto al Hospital real ya conocemos por la permanencia en él de nuestro personaje» ${ }^{74}$. Hagamos un pequeño análisis del tema para ver la realidad asistencial de la época.

Mejor documentado Henríquez de Jorquera ${ }^{75}$, nos presenta en 1609, 13 Hospitales: Hospital Real, Hospital de San Lázaro, Hospital del Arzobispo, Hospital General, Hospital del Corpus Christi, Hospital de Caridad, Hospital de Navas, Hospital de San Sebastián, Convalecencia de San Juan de Dios, Hospital de la Madre de Dios, Hospital de los Peregrinos, Hospital y casa del arte de la seda, Hospital San Juan de Dios ${ }^{76}$.

Todos se encontraban en Granada capital y coinciden prácticamente con un documento inédito que encontramos en el Archivo General de Simancas, y que analizaremos detalladamente: él nos sitúa desde 1568, en la realidad hospitalaria de la época, a pocos años de la muerte del Santo. El documento inédito sobre los Hospitales de Granada, del AGS ${ }^{77}$, es un manuscrito de 58 páginas. Lo presentamos en el Apéndice final con el número 35. En el f. 1 dice: hospitales de Granada, son 13 hospitales, 6 no se reduzcan. Las advertencias, no son del arzobispo sino del provisor ${ }^{78}$.

Gracias al documento encontrado en Simancas sobre los hospitales de Granada, podemos tener una idea más precisa de la labor asistencial que se desarrollaba en la ciudad y en la provincia. En la ciudad había 10 hospitales aumentando a once con el que fundó Juan de Dios. Eran los siguientes: «Y cumpliendo con lo que Vuestra Majestad manda, digo que en esta çiudad de Granada ay trece hospitales que son estos: El Real, el de Santa Ana, el de San Lázaro, el de la Caridad, el de Ramírez de Alarcon, el de El Albayzin u Hospital General para moriscos, el del Corpus Christi, el de Peregrinos, el de San Lázaro, el de la Hermandad de la seda, el doctor Quexada, el de Juan de Dios» ${ }^{79}$.

74 José CRUSET, Una aventura iluminada, 179.

75 Francisco Enríquez de Jorquera, Análisis de Granada. Sucesos de los años 1588-1646. Edición preparada, según el manuscrito original, por Antonio Marín Ocete, Publicaciones de la Facultad de Letras, Granada, 1934, dos tomos.

76 Ibid., Análisis, I, 256-261.

77 José Luis MarTínEZ, o. c., AP, n. ${ }^{\circ}$ 35, AGS, Ms., Patronato Eclesiástico, Legajo 39, sin paginar. En la portada trae una p. 40 . Son 58 folios manuscritos. Es la respuesta del arzobispo de Granada a dos cartas de Felipe II, donde le pide le envíe una relación de los hospitales de Granada y su jurisdicción con sus rentas y cofradías y juntamente con el parecer del corregidor y dos regidores, den su parecer para la reducción de hospitales en uno o dos al Consejo de S. M., ff. 1-3.

78 Ibid., AP, n. ${ }^{\circ} 35$, AGS, P. E, leg. 39, f. 1.

79 Ibid., AP, n. 35 . 
Hay que excluir el de San Sebastián y el de Convalecientes de Ramírez de Alarzón, según el mismo documento: el primero fue fundado en 1551, después de la muerte del santo; y el segundo, lo fundó el licenciado Ramírez por donación de vivos, el 14 de agosto de $1564^{80}$.

Del documento podemos deducir la cantidad, muy aproximada, de las camas que contaba Granada en tiempo del Santo: 188 camas de los 11 hospitales citados que había en la ciudad; más cincuenta camas que aporta el Hospital que fundó Juan de Dios. En total, unas 238 camas. Debemos añadir las camas de los 11 hospitales de la provincia: La Vega, Sierra, Siete Villas, Santa Fe, Puente de Pinos, Albelote, Loja, Alhama, Almuñécar, Motril y Salobreña, con unas 42 camas, que suman un total de 280. A los pocos años, en 1571, el Hospital de Juan de Dios, según la Súplica que presentan a San Pío V pidiéndole el traslado del cuerpo del Santo de la Iglesia de Santa María de la Paz a la de su Hospital, dicho documento señala 250 enfermos $^{81}$. Lo que en 1585 , año del documento anteriormente citado, supone ya la confortable cifra de 482 camas $^{82}$.

El arzobispo de Granada, D. Juan Méndez de Salvatierra, no respondió en ese momento a la carta que sobre la reducción de Hospitales le había escrito Felipe II y apunto alguna razón: primera, «pudo ser porque entonces se levantaron los moriscos deste reyno» y no era el momento adecuado, y segunda, «o porque en este arzobispado ay tan pocos hospitales y tan proves que parece no ser necesaria esta reducción», no estaban mentalizados a ella y no pensaban en una hospitalidad de calidad sino socorrer al enfermo como fuera ${ }^{83}$.

Estos hospitales se encontraban en la capital de Granada y vienen prácticamente a coincidir con el documento que venimos comentando encontrado en el Archivo General de Simancas, y que nos sitúa, desde 1568, en la realidad hospitalaria de la época, pocos años de la muerte de Juan de Dios. Su repercusión, su prestigio era ya significativo y el gran avance dado en la hospitalidad, era tenido en cuenta por los ciudadanos, de ahí las donaciones que dejan y reciben los Hermanos desde el primer momento.

Significa que valoran, estiman y aprecian la labor que siguen desarrollando los primeros Hermanos y continuadores del santo de su acción caritativa. El documento inédito está en el $\mathrm{AGS}^{84}$.

\footnotetext{
80 Ibid., AP, 35.

81 Ibid., AP, n. ${ }^{\circ} 10$.

82 Ibid., AP, n. ${ }^{\circ} 35$.

83 Ibid., AP, 35, f. 2.

84 Ibid., 35, ff. 1-3.
}

Hispania Sacra, Estudios de Edad Moderna, 58

117, enero-junio 2006, 69-100, ISSN: 0018-215-X 


\subsection{Hospitales de Granada en tiempo de Juan de Dios}

\begin{tabular}{|c|c|c|c|c|c|c|c|}
\hline HOSPITALES & Enfermedades & $\begin{array}{l}\text { Hom- } \\
\text { bres }\end{array}$ & $\begin{array}{l}\text { Mu- } \\
\text { jeres }\end{array}$ & Niños & $\begin{array}{l}\text { TITULARIDAD } \\
\text { Parroquia }\end{array}$ & $\begin{array}{c}\text { RENTAS } \\
\text { Donaciones }\end{array}$ & $\begin{array}{l}\text { CA- } \\
\text { MAS }\end{array}$ \\
\hline $\begin{array}{l}\text { HOSPITAL } \\
\text { REAL }\end{array}$ & Bubas y locos & $16+20$ & 8 & & Patronato Real & $1.007 .080 \mathrm{~m}$ & 44 \\
\hline $\begin{array}{l}\text { JUAN } \\
\text { DE DIOS }\end{array}$ & General & $45+50$ & $15-20$ & $5-10$ & Juan de Dios & $2 c+237.150 \mathrm{~m}$ & $60-70$ \\
\hline SANTA ANA & General & 30 & 24 & & $\begin{array}{l}\text { Parroquia } \\
\text { Santa Ana }\end{array}$ & $\begin{array}{l}333.000 \mathrm{~m}+1 \mathrm{c} \\
500 \mathrm{t} . \\
+300 \text { fanegas }\end{array}$ & 20 \\
\hline $\begin{array}{l}\text { El de } \\
\text { LA CARIDAD }\end{array}$ & $\begin{array}{l}\text { Calenturas, } \\
\text { enfermedades } \\
\text { no contagiosas }\end{array}$ & & 20 & & $\begin{array}{l}\text { P. San Gil y la } \\
\text { Congregación }\end{array}$ & Solo limosnas & 20 \\
\hline $\begin{array}{l}\text { RAMÍREZ DE } \\
\text { ALARÇON }\end{array}$ & Convalecientes & & 6 & & $\begin{array}{l}\text { Parroquia } \\
\text { Santa } \\
\text { Escolástica }\end{array}$ & $\begin{array}{l}362.101+ \\
\text { Casas+censos }\end{array}$ & 6 \\
\hline $\begin{array}{l}\text { EL CORPUS } \\
\text { CHRISTI }\end{array}$ & $\begin{array}{l}\text { Heridos+ } \\
\text { expósitos }\end{array}$ & & & 4 & $\begin{array}{l}\text { Parroquia } \\
\text { San Gil }\end{array}$ & $\begin{array}{l}\text { Censos } \\
\text { perpetuos }\end{array}$ & 4 \\
\hline EL ALBAYCIN & General & 6 & 4 & & $\begin{array}{l}\text { Naturales- } \\
\text { Moriscos }\end{array}$ & $\begin{array}{l}600 \text { ducados } \\
\text { Su colabo- } \\
\text { ción }\end{array}$ & 10 \\
\hline $\begin{array}{l}\text { El de } \\
\text { PEREGRINOS }\end{array}$ & $\begin{array}{l}\text { Peregrinos+ } \\
\text { mendigos }\end{array}$ & 8 & & & $\begin{array}{l}\text { P. San Gil } \\
\text { Madre de Dios }\end{array}$ & $47.00 \mathrm{~m}$ & 8 \\
\hline $\begin{array}{l}\text { El de } \\
\text { SAN LÁZARO }\end{array}$ & $\begin{array}{l}\text { Lepra y fuego } \\
\text { San Antonio }\end{array}$ & 10 & 5 & & $\begin{array}{l}\text { P. S. Ildefonso } \\
\text { Mayordomo }\end{array}$ & $26.000 \mathrm{~m}$ & 15 \\
\hline $\begin{array}{l}\text { HERMANDAD } \\
\text { DE LA SEDA }\end{array}$ & Convalecientes & 4 & 2 & & $\begin{array}{l}\text { P. S. Matías } \\
\text { Mayordomo }\end{array}$ & $\begin{array}{l}297.666 \text { m+ } \\
\text { Limosnas } \\
\text { suyas }\end{array}$ & 6 \\
\hline $\begin{array}{l}\text { HOSPITAL } \\
\text { GENERAL DE } \\
\text { MORISCOS }\end{array}$ & General & 15 & 5 & & $\begin{array}{l}\text { Parroquia } \\
\text { San Nicolás }\end{array}$ & $\begin{array}{l}947.896 \mathrm{~m} \\
\text { Grandes rentas }\end{array}$ & 20 \\
\hline
\end{tabular}


Personal que atiende a los Hospitales de Granada. Sueldos. Especies. Raciones que perciben

\begin{tabular}{|c|c|c|c|}
\hline $\begin{array}{c}\text { PERSONAL } \\
\text { PROFESIONAL }\end{array}$ & SUELDO ANUAL & ESPECIES & RACIONES \\
\hline $\begin{array}{l}\text { ABOGADOS } \\
\text { CIRUJANO } \\
\text { MEDICO } \\
\text { MEDICO } \\
\text { MAYORDOMO de } 1 .^{\mathrm{a}} \\
\text { MAYORDOMO de } 2 .^{\mathrm{a}} \\
\text { MAYORDOMO de } 3 .^{\mathrm{a}} \\
\text { MAYORDOMO de } 4 .^{\mathrm{a}} \\
\text { CAPELLÁN } \\
\text { CAPELLÁN } \\
\text { RECTOR } \\
\text { VEEDORES } \\
\text { LIMOSNERO } \\
\text { ENFERMERO MAYOR } \\
\text { ENFERMERA MENOR } \\
\text { ENFERMEROS Menores } \\
\text { CUIDADOR DE LOCOS } \\
\text { CUIDADOR-MUNIDOR } \\
\text { HOSPITALERO } \\
\text { ENFERMERA Auxiliar } \\
\text { SIRVIENTA } \\
\text { DESPENSERO } \\
\text { PORTERO } \\
\text { COCINERA MAYOR } \\
\text { VIGILANTES } \\
\text { ESCRIBANO } \\
\text { SECRETARIO } \\
\text { CONTADOR } \\
\text { BARBERO } \\
\text { RELOJERO } \\
\text { PROCURADOR } \\
\text { EL AMA } \\
\text { PATRON } \\
\text { MINISTROS }\end{array}$ & $\begin{array}{l}4 \text { ducados } \\
14 \text { ducados } \\
20.000 \mathrm{mrs} \\
12 \text { ducados } \\
50.000 \mathrm{mrs} \\
550.000 \mathrm{mrs} \\
26.140 \mathrm{mrs} \\
5.000 \mathrm{mrs} \\
16.224 \mathrm{mrs} \\
9 \text { ducados } \\
12.000 \mathrm{mrs} \\
10.000 \mathrm{mrs} \\
10.000 \mathrm{mrs} \\
4.350 \mathrm{mrs} \\
4.000 \mathrm{mrs} \\
5.586 \mathrm{mrs} \\
4.500 \mathrm{mrs} \\
12 \mathrm{reales} \\
13.474 \mathrm{mrs} \\
12.240 \mathrm{mrs} \\
15.546 \mathrm{mrs} \\
9.000 \mathrm{mrs} \\
3.120 \mathrm{mrs} \\
2.856 \mathrm{mrs} \\
2 \text { ducados } \\
3.000 \mathrm{mrs} \\
3.000 \mathrm{mrs} \\
4.500 \mathrm{mrs} \\
7.000 \mathrm{mrs} \\
4.500 \mathrm{mrs} \\
1.000 \mathrm{mrs} \\
18 \mathrm{reales} \\
2.000 \mathrm{mrs} \\
144.929 \mathrm{mrs}\end{array}$ & $\begin{array}{l}30 \text { fanegas de cebada } \\
24 \text { fanegas de trigo } \\
24 \text { fanegas de trigo }\end{array}$ & $\begin{array}{c}2 \text { raciones } \\
1 \text { ración y } \\
\text { media } \\
1 \text { ración } \\
1 \text { ración } \\
2 \text { raciones } \\
2 \text { raciones } \\
1 \text { ración } \\
1 \text { ración } \\
2 \text { raciones } \\
2 \text { raciones } \\
1 \text { ración } \\
1 \text { ración } \\
1 \text { ración }\end{array}$ \\
\hline $\begin{array}{c}\text { TOTAL } \\
\text { PROFESIONALES (34) }\end{array}$ & $\begin{array}{l}43 \text { ducados }+ \\
939.495 \mathrm{mrs}+ \\
30 \text { reales }\end{array}$ & $\begin{array}{c}66 \text { fanegas de cebada }+ \\
60 \text { fanegas } \\
\text { de trigo }\end{array}$ & $\begin{array}{c}18 \text { raciones y } \\
\text { media }+1 \\
\text { cahíz de trigo } \\
\text { y cebada }\end{array}$ \\
\hline
\end{tabular}

Hispania Sacra, Estudios de Edad Moderna, 58

117, enero-junio 2006, 69-100, ISSN: 0018-215-X 
Una ración consistía en: 1 libra de carnero + dos de pan y media de azumbre de vino.

Salarios de los Ministros: Total: 144.820 M.

Montan: raciones de carne, vino y libras de carnero $(20 \mathrm{~m})+$ el vino en $16 \mathrm{~m}$.

Total de las Raciones: $141.629 \mathrm{~m}$.

El pan tasándose a fanega por ración son 163 fanegas de trigo; con más de 24 fanegas que se dan al veedor de los locos. + 12 fanegas al secretario y otras 12 al administrador de agua son total 186 fanegas de cebada; 30 fanegas al mayordomo y 36 fanegas al médico.

$\mathrm{Al}$ año se dan $11.000 \mathrm{~m}$. de aguinaldo a los oficiales.

Ensolar los tres hornos y aderezar la casa de agua:

$20.000 \mathrm{~m}$.

De porte del trigo de limosna y portes de la casa tiene

$15.000 \mathrm{~m}$.

Renta Total del Hospital: $862.249 \mathrm{~m}$.

Salarios Raciones: $367.558 \mathrm{~m}$.

Quedan para hacer Hospitalidad: $494.691 \mathrm{~m}$.

Renta del Hospital: 1.580 fanegas de trigo

293 fanegas de cebada.

Limosnas de los Reyes Católicos:

1.105 fanegas de trigo.

66 fanegas de cebada.

En los ministros se gastan 186 fanegas de trigo y 227 fanegas de cebada.

1. Hospital de Loja: Mayordomo: 2.000 Ducados para hacer hospitalidad.

2. Alhama: 99.000 M. + 200 Fanegas de trigo +100 de cebada.

3. Almuñecar: $100.000 \mathrm{~m}$. en hospitalidad a los pobres y enfermos.

4. Motril: $80.000 \mathrm{~m}$. Para hospitalidad a los pobres y enfermos

5. Salobreña: $34.000 \mathrm{~m}$. Para hospitalidad de los pobres y enfermos.

6. Santa Fe, Puente Pinos, Albolote: $250.000 \mathrm{~m}$. +1000 fanegas de trigo, +500 de cebada. Para hospitalidad de los pobres y enfermos.

Realizado el Proceso de Beatificación que comenzó en 1622, en Granada, Madrid, Úbeda, Salamanca, Ocaña, Utrera, Córdoba, Martos, Segovia, Oropesa, Toledo, Alcaraz, Palencia, Valladolid, Cabra, Porcuna, Sanlúcar, Cádiz, Lopera, Medina Sidonia, Montemayor el Nuevo, Jerez de la Frontera, Jaén, Lucena, Osuna. Fue enviado a Roma en 1624. Felizmente concluido fue aprobado por la Sagrada Congregación de Ritos con el decreto el día 8 de junio de 1630 Transmissis de mandato, Urbano VIII asintió el 7 de septiembre de 1630. Por medio del Breve In Sede Principis Apostolorum, el 21 de septiembre el mismo Papa aprobaba el Decreto anterior y lo Beatificó. Habían pasado ochenta años de su santa muerte. Con tal motivo se celebraron grandes fiestas en todos los 
Hospitales de la Orden. En 1690, el 16 de octubre, tuvo lugar en la Basílica de San Pedro una bella ceremonia donde Alejandro VIII lo canonizó. El Papa León XIII lo nombró Patrono de los enfermos, colocando su nombre en las Letanías de los Agonizantes. Pío XI lo proclamó Patrono de los Enfermeros y de cuantos se dedican a la asistencia de los enfermos y Pío XII se dignó nombrarle Copatrono de Granada. Es Patrono del benemérito e Ilustre Cuerpo de Bomberos. 